\title{
Systematic Investigation of Ergosterol Fermentation by Kluyveromyces marxianus Y.00243 via Statistical Design
}

\author{
Aladár Vidra', Zoltán Kaleta², Áron Németh* \\ 1 Department of Applied Biotechnology and Food Science, Faculty of Chemical Technology and Biotechnology, Budapest \\ University of Technology and Economics, H-1111 Budapest, Budafoki út 6-8., Hungary \\ 2 Progressio Engineering Bureau Ltd., H-1028 Budapest, Muhar u. 54, Hungary \\ * Corresponding author, e-mail: naron@f-labor.mkt.bme.hu
}

Received: 15 March 2021, Accepted: 02 June 2021, Published online: 16 August 2021

\begin{abstract}
Ergosterol, an important pharmaceutical intermediate, is the precursor of liposoluble vitamin $\mathrm{D}_{2}$ and cortisone. It is also a main sterol in yeast cells and responsible for structural features of membranes such as the integrity, fluidity, permeability and activity of membrane-bound enzymes. Kluyveromyces marxianus is able to utilize various sugars such as lactose, xylose and arabinose against Saccharomyces cerevisiae and is also thermotolerant. Based on these aforementioned characteristics, $K$. marxianus can be of great importance in the utilization of whey and lignocellulosic biomass. In this paper, the effect of four factors on the specific ergosterol content and yeast growth was investigated using two statistical experimental designs. The factors examined were initially added alcohol, temperature, salt concentration and $\mathrm{pH}$. The initially added alcohol had a positive effect on the specific ergosterol content, resulted in $37 \%$ specific ergosterol content increasement. The temperature had a negative effect on yeast growth reducing the biomass concentration by $50 \%$ when increased from $25^{\circ} \mathrm{C}$ to $30^{\circ} \mathrm{C}$. The $\mathrm{pH}$ had a significant effect only on the specific ergosterol content, having an optimum at pH 5.5. The salt concentration had no significant effect in either case. Based on the results, it is suggested that the setup which facilitates higher ergosterol content but does not slow down the growth of the yeast remarkably should be selected, which are $25^{\circ} \mathrm{C}, \mathrm{pH} 5.3$ and $3 \%$ of initial ethanol content.
\end{abstract}

Keywords

ergosterol, Kluyveromyces marxianus, experimental design, ethanol addition, optimization

\section{Introduction}

Kluyveromyces marxianus is a hemiascomycetous and homothallic yeast, phylogenetically close to Kluyveromyces lactis. In contrast to Saccharomyces cerevisiae, K. marxianus is capable of assimilating a variety of sugars such as lactose which is found in whey as well as xylose and arabinose which are contained in lignocellulosic biomass hydrolysates $[1,2]$. For this reason, this yeast has been widely used for the production of biomolecules of economic and biotechnological interests, e.g. using enzymes such as $\beta$-galactosidase, inulinase and pectinase as well as recombinant proteins, aroma compounds and ethanol [3-8].

In addition to the fermentation of lactose, $K$. marxianus has other desirable attributes for industrial fermentation processes such as thermotolerance, high growth rate and the capacity to metabolize pentose, hexose and disaccharides $[9,10]$. Since, for years, it used to mainly be isolated from dairy products, it possesses the GRAS (Generally
Recognized As Safe) and QPS (Qualified Presumption of Safety) statuses, therefore, making it suitable for applications in the food and pharmaceutical industries [11-13]. Ergosterol is one of the most economically important components of yeast biomass which could be used as a precursor of vitamin $\mathrm{D}_{2}$ and other sterol drugs such as cortisone, brassinolide and progesterone $[14,15]$. In yeast cells, ergosterol is found stored in its free form in plasma membrane and as esters of fatty acids $[16,17]$. Similarly to the cholesterol in mammalian cells, sterol plays the main role in ensuring the integrity of cellular membranes and controlling their functions of fluidity, permeability and transport as well as the activity of proteins in plasma membranes and the cell cycle [2, 18-20]. Ergosterol not only has unique physiological functions but is also widely used in drug development [21]. Most antifungal drugs in clinical use are developed to inhibit the key enzymes of ergosterol 
biosynthesis [22]. Furthermore, derivatives of ergosterol perform significant antitumor and anti-HIV activities [23, 24]. Ergosterol is also very important for adaptation to stress in fungi. It has been found that the ability of yeast to tolerate stress is closely related to ergosterol levels. For example, the ergosterol content of yeasts that are resistant to freezing and low-sugar conditions or are treated with alcohol is higher than that of common yeast [25-27].

Ergosterol is mainly produced by two different methods. Firstly, ergosterol can be extracted from waste mycelium used in the production of penicillin or during the fermentation of citric acid. Secondly, ergosterol can also be produced by the fermentation of yeast. In the former method, the necessary raw materials are much cheaper, but the ergosterol content of mycelium is lower than that of yeast $[28,29]$.

Since ergosterol also plays an essential role in terms of adaptation to stress during fermentation, it follows that cells growing under different conditions of environmental stress can accumulate more ergosterol. Therefore, in this study, the effects of the $\mathrm{pH}$ and temperature as well as ethanol addition were investigated in the first experimental design. Furthermore, the effects of the $\mathrm{pH}$ (over a wider range) and salt concentration were investigated in a second experimental design. With different $\mathrm{NaCl}$ concentration we intended to examine if this type of osmotic stress had any effect on ergosterol content of cells. Both the ergosterol content of the cells and growth of the yeast cells were examined using response surface methodology.

\section{Materials and methods}

\subsection{Microorganism and maintenance}

K. marxianus strain Y.00243 originated from the National Collection of Agricultural and Industrial Microorganisms (NCAIM) in Budapest, Hungary.

Lyophilized yeast was reactivated in $1 \mathrm{~mL}$ of $\mathrm{YM}$ medium (yeast extract: $3 \mathrm{~g} / \mathrm{L}$, malt extract $3 \mathrm{~g} / \mathrm{L}$ ) for 2-3 mins then cultured aseptically on solid agar plates (20 g/L malt extract and $20 \mathrm{~g} / \mathrm{L}$ agar in distilled water) previously sterilized in a Tuttnauer 3870 ELV (Belgium) autoclave at $121{ }^{\circ} \mathrm{C}$ for $20 \mathrm{~min}$. The inoculated solid medium was incubated at $30{ }^{\circ} \mathrm{C}$ for 4 days to facilitate the appropriate degree of growth before being stored at $5{ }^{\circ} \mathrm{C}$ for further use.

\subsection{Inoculum preparation}

Inoculum was prepared in 100-mL Erlenmeyer flasks containing $50 \mathrm{~mL}$ of the inoculum medium (consisting of $10 \mathrm{~g} / \mathrm{L}$ glucose, $3 \mathrm{~g} / \mathrm{L}$ yeast extract and $10 \mathrm{~g} / \mathrm{L}$ peptone in distilled water) previously autoclaved at $121{ }^{\circ} \mathrm{C}$ for $20 \mathrm{~min}$. The incubation was carried out whilst constantly being shaken at $250 \mathrm{rpm}$ at $30{ }^{\circ} \mathrm{C}$ for $72 \mathrm{~h}$ in a New Brunswick Scientific incubator shaker, model Innova 40R (Connecticut, USA). The required $5 \%$ inoculum was transferred aseptically into the fermentation broth.

\subsection{Fermentation conditions}

Experiments were caried out in 250-mL Erlenmeyer flasks containing $100 \mathrm{~mL}$ of fermentation broth composed of the following: $20 \mathrm{~g} / \mathrm{L}$ lactose, $20 \mathrm{~g} / \mathrm{L}$ yeast extract, $7 \mathrm{~g} / \mathrm{L} \mathrm{NaNO}_{3}, 6 \mathrm{~g} / \mathrm{L} \mathrm{K}_{2} \mathrm{HPO}_{4}, 3 \mathrm{~g} / \mathrm{L} \mathrm{MgSO} \mathrm{Mg}_{4} \cdot 7 \mathrm{H}_{2} \mathrm{O}$, $1 \mathrm{mg} / \mathrm{L} \mathrm{FeCl}_{3} \cdot 6 \mathrm{H}_{2} \mathrm{O}, 10 \mathrm{mg} / \mathrm{L} \mathrm{ZnSO}_{4} \cdot 7 \mathrm{H}_{2} \mathrm{O}$ and $1 \mathrm{mg} / \mathrm{L} \mathrm{CuSO}_{4} \cdot 5 \mathrm{H}_{2} \mathrm{O}$ [30]. The lactose content was sterilized separately. Unless otherwise stated, a temperature of $25{ }^{\circ} \mathrm{C}$ was applied. The incubation was carried out under constant shaking at $250 \mathrm{rpm}$. The prescribed ethanol addition was carried out before inoculation.

\subsection{Experimental design}

In order to study the effect of factors on ergosterol fermentation two central composite designs with three and two factors, respectively, were applied. All the factors were tested at three different levels. The investigated factors and their values are listed in Tables 1 and 2 for the two experimental designs, respectively.

The first experimental design was a face-centred central composite design with 3 factors at three different levels as presented in Table 1.

Table 1 Settings of the first experimental design

\begin{tabular}{lccc}
\hline Standard run & Temperature $\left({ }^{\circ} \mathrm{C}\right)$ & $\mathrm{pH}$ & Ethanol (\%) \\
\hline 2 & 25 & 4.5 & 10 \\
1 & 25 & 4.5 & 0 \\
9 & 25 & 5.5 & 5 \\
3 & 25 & 6.5 & 0 \\
4 & 25 & 6.5 & 10 \\
11 & 30 & 4.5 & 5 \\
13 & 30 & 5.5 & 0 \\
$16(\mathrm{C})$ & 30 & 5.5 & 5 \\
$15(\mathrm{C})$ & 30 & 5.5 & 5 \\
14 & 30 & 5.5 & 10 \\
12 & 30 & 6.5 & 5 \\
6 & 35 & 4.5 & 10 \\
5 & 35 & 4.5 & 0 \\
10 & 35 & 5.5 & 5 \\
8 & 35 & 6.5 & 10 \\
7 & 35 & 6.5 & 0 \\
\hline
\end{tabular}


Table 2 Settings of the second experimental design

\begin{tabular}{lcc}
\hline Standard run & $\mathrm{pH}$ & $\mathrm{NaCl}(\mathrm{g} / \mathrm{L})$ \\
\hline 2 & 3.5 & 20.0 \\
7 & 5.5 & 1.9 \\
8 & 5.5 & 23.1 \\
3 & 7.5 & 5.0 \\
1 & 3.5 & 5.0 \\
$9(\mathrm{C})$ & 5.5 & 12.5 \\
6 & 8.3 & 12.5 \\
5 & 2.7 & 12.5 \\
$10(\mathrm{C})$ & 5.5 & 12.5 \\
4 & 7.5 & 20.0 \\
\hline
\end{tabular}

The second experimental design was a central composite design with two factors at three different levels as presented in Table 2.

The outputs of the experiments were the dry cell weight, the specific ergosterol content of the biomass $(\mathrm{mg} / \mathrm{g})$ and the ergosterol concentration in the extract $(\mathrm{mg} / \mathrm{mL})$. The ANalysis Of VAriance (ANOVA) was used to gain preliminary information about the effect of the factors.

The applied quadratic polynomial response model was given by this equation:

$\hat{Y}=\beta_{0}+\sum_{i=1}^{k} \beta_{i} X_{i}+\sum_{i=1}^{k} \beta_{i i} X_{i}^{2}+\sum_{i=1}^{k} \sum_{j=1}^{k} \beta_{i j} X_{i} \beta_{i i} X_{j}+\varepsilon$,

where $\hat{Y}$ denotes the predicted response variable, $X_{i}$ stands for the independent variable, $\beta_{0}, \beta_{i}$, $\beta_{i i}$ and $\beta_{i j}$ refer to the regression coefficients and $\varepsilon$ represents the random error.

\subsection{Software}

Statistica 13.1 software (StatSoft, Inc., Tulsa, USA) was used for the statistical and graphical evaluation of the experimental results.

\subsection{Determination of ergosterol}

The fermentation broth was centrifuged at 4,000 rpm for $15 \mathrm{~min}$ by an Hermle Z200A centrifuge. Sediments of $15 \mathrm{ml}$ fermentation broth were placed into $1.5-\mathrm{mL}$ Eppendorf tubes and diluted with $750 \mu \mathrm{L}$ of $8 \% \mathrm{NaOH}$ solution. After homogenization, it was maintained at $85^{\circ} \mathrm{C}$ for $2 \mathrm{~h}$. After cell disruption, the solution was centrifuged at 13,000 rpm for $5 \mathrm{~min}$.

Ergosterol was extracted from the sediment consecutively three times using $96 \%$ ethanol as follows. The sediment was suspended in $750 \mu \mathrm{L}$ ethanol, homogenized for $5 \mathrm{~min}$ and then centrifuged at 13,000 rpm for $5 \mathrm{~min}$. The supernatant was collected in another tube.
This procedure was repeated twice but by applying $500 \mu \mathrm{L}$ of ethanol twice and the 3 supernatants were combined resulting in $1.75 \mathrm{~mL}$ of ethanolic solution altogether [31].

The collected ethanolic supernatant was quantified for ergosterol with HPLC (High-Performance Liquid Chromatography) (Shimadzu, Japan) measurements with a Kinetex XB-C18 column operated at room temperature eluted by acetonitrile as the mobile phase at a flow rate of $1 \mathrm{~mL} / \mathrm{min}$. For standard solutions HPLC grade ergosterol (Sigma-Aldrich) was used. Samples were diluted tenfold and $10 \mu \mathrm{L}$ was injected. Ergosterol content was detected by a UV Detector at wavelength of $280 \mathrm{~nm}$ at room temperature.

Dry cell weight was measured by Sartorius MA35 Moisture Analyzer at $105^{\circ} \mathrm{C}$.

\section{Results and discussion}

The first experimental design was used to gain information about the effect of the temperature, ethanol and $\mathrm{pH}$ on the ergosterol content of yeast cells and yeast growth. The effects of these three factors are shown in Fig. 1 where the vertical line denotes the threshold of significance.

The linear effect of the temperature and the effect of the interaction between temperature and ethanol were significant in terms of yeast growth. The temperature of $25^{\circ} \mathrm{C}$ was favourable for cell growth. In contrast, at slightly higher temperatures, significantly lower biomass was produced. In contrast, Actaş et al. [32] reported that some $K$. marxianus strains have higher metabolic activity at higher temperature. However, Costa et al. [33] studied the growth of three different strains of $K$. marxianus at different temperatures and in the presence of different alcohol concentrations. Their results similarly to ours showed

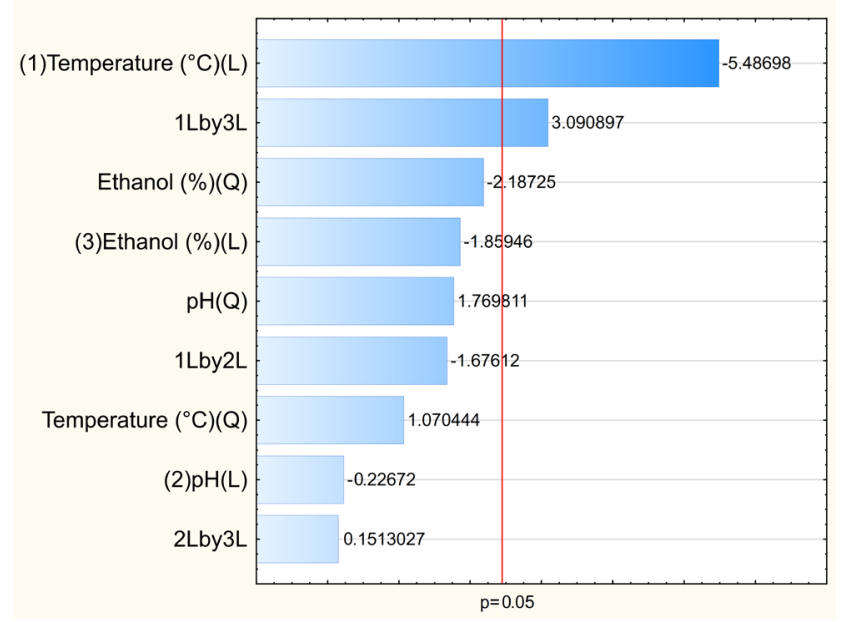

Fig. 1 Pareto chart of dry cell weight concentration in the first experimental design (L: Linear, Q: Quadratic) 
that different strains tolerate higher temperatures differently i.e. our strain was less suitable for use at higher temperatures [33]. The addition of ethanol had no significant effect on cell growth, however when $10 \%$ ethanol was introduced, lower concentration of biomass was observed. This behavior was also consistent with the results obtained by Costa et al. [33]. As is shown in Fig. 2, the higher concentration values of dry cell weight, about $11.5 \mathrm{~g} / \mathrm{L}$, were reached in the range of $0-4 \%$ of alcohol.

The two other factors had no significant effect on cell growth within the examined range.

Evaluation of the results in terms of the specific ergosterol content of the cells concluded that the effect of the initially added alcohol and the interaction between the $\mathrm{pH}$ and alcohol proved to be significant as presented in Fig. 3.

In this case, the effect of the volume of the initially added ethanol has a maximum within the examined range as can be seen in Fig. 4. The highest value, $5 \mathrm{mg} / \mathrm{g}$ was reached

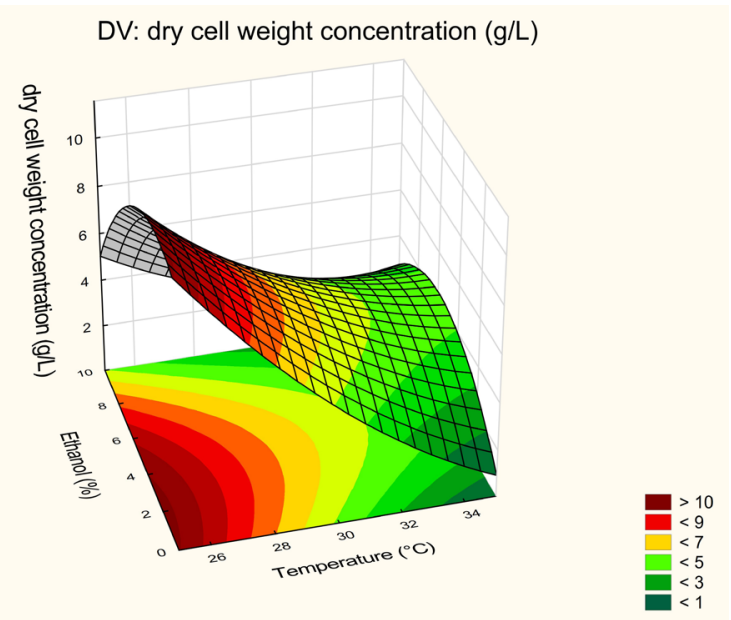

Fig. 2 The response surface plot of dry cell weight concentration as a function of ethanol and temperature

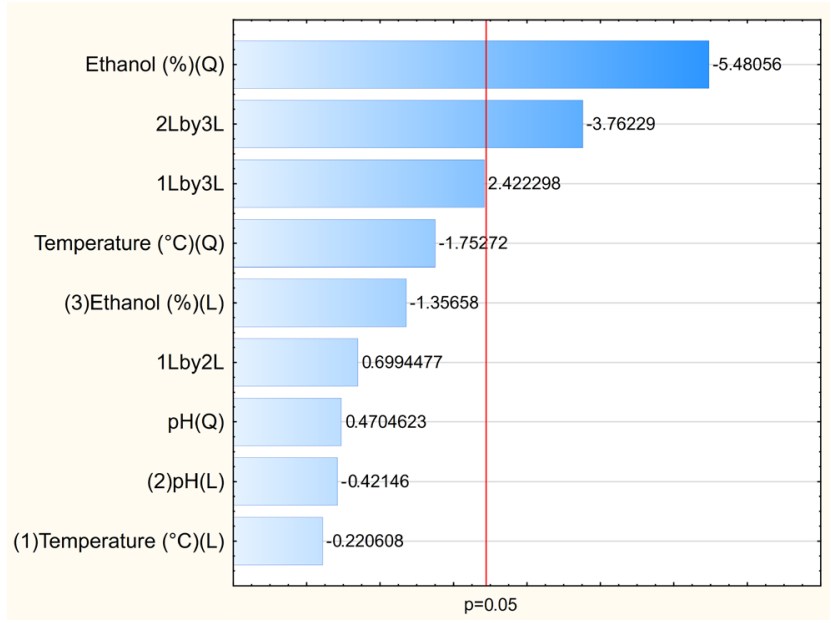

Fig. 3 Pareto chart of the specific ergosterol content of the cells in the first experimental design (L: Linear, Q: Quadratic)
DV: Specific ergosterol content $(\mathrm{mg} / \mathrm{g})$

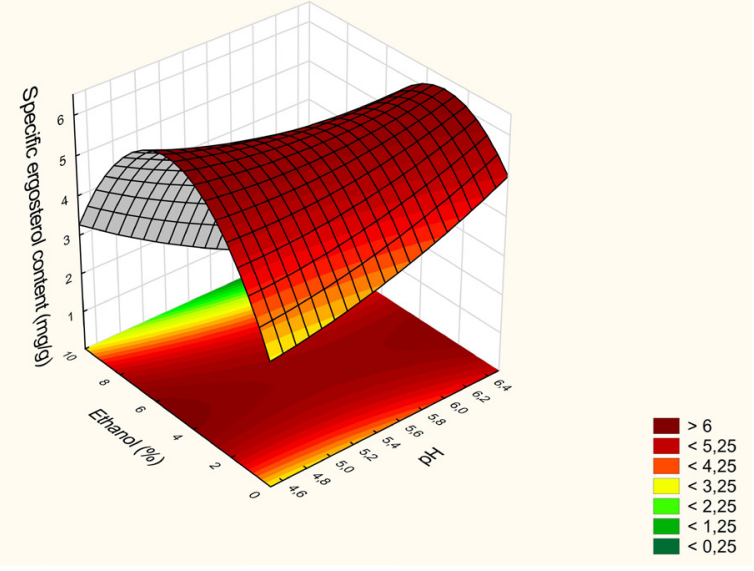

Fig. 4 Specific ergosterol content as a function of ethanol and $\mathrm{pH}$

using $4.6 \%$ ethanol. It can be seen that by increasing the amount of alcohol added, the specific ergosterol content of the cells increased. Despite the fact, Diniz et al. [1] found that ethanol exposure decreased the expression of some genes involved in ergosterol biosynthesis and as a consequent ergosterol content did not changed in $K$. marxianus, Fu et al. [34] studied the response of cells to ethanol stress at gene level and found that cells increased their ergosterol content similarly to our results. The interaction between the ethanol and $\mathrm{pH}$ was also visible as the saddle surface was slightly inclined.

Based on the above, it could be observed that different settings were suitable for cell growth and higher specific ergosterol content. To evaluate the overall effect of factors, a virtual ergosterol concentration was calculated from the amount of ergosterol extracted (in $\mathrm{mg}$ ) and the volume of fermentation broth used (in L).

The initially added ethanol was again a highly significant factor with linear and quadratic effects, as can be seen in Fig. 5. The effect of the temperature was also significant. Furthermore, the interaction between the temperature and alcohol as well as the interaction between the $\mathrm{pH}$ and alcohol also proved to be significant.

By representing the effect of the alcohol and $\mathrm{pH}$ on the extractable amount of ergosterol $\mathrm{mg}$ ergosterol/L fermentation broth was plotted in Fig. 6. The highest value, $78 \mathrm{mg} / \mathrm{L}$ was obtained by initially adding $3 \%$ alcohol. Interestingly, the optimal growth of $K$. marxianus at $\mathrm{pH} 5.5$ is the least suitable for the production of ergosterol in terms of the virtual ergosterol concentration (the amount of extractable ergosterol in $\mathrm{mg}$ / volume from the volume of fermentation broth used in L). Previously, it has been observed that this microorganism did not grow well in the presence of high concentrations of alcohol [33], 


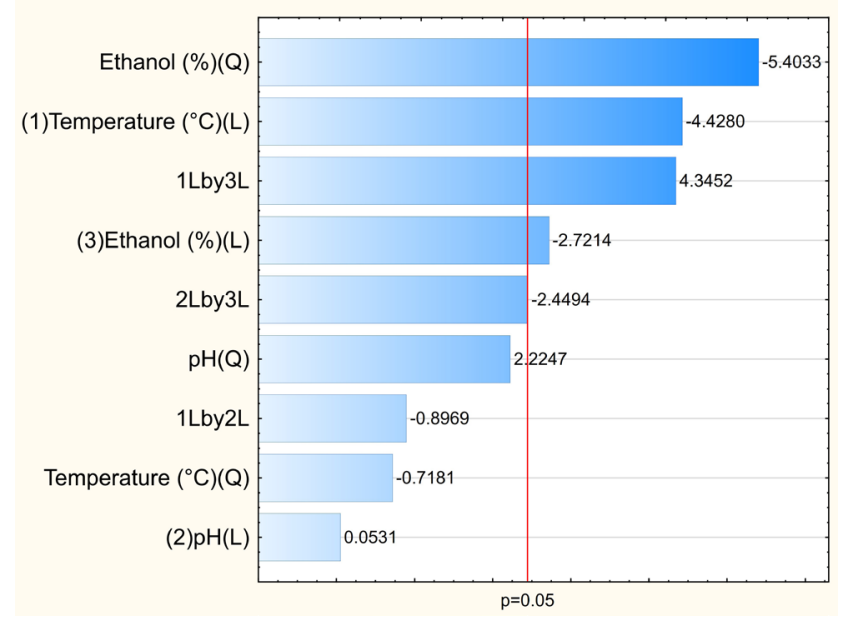

Fig. 5 Pareto chart of the virtual ergosterol concentration in the first experimental design (L: Linear, Q: Quadratic)

DV: Virtual ergosterol concentration (mg/L)

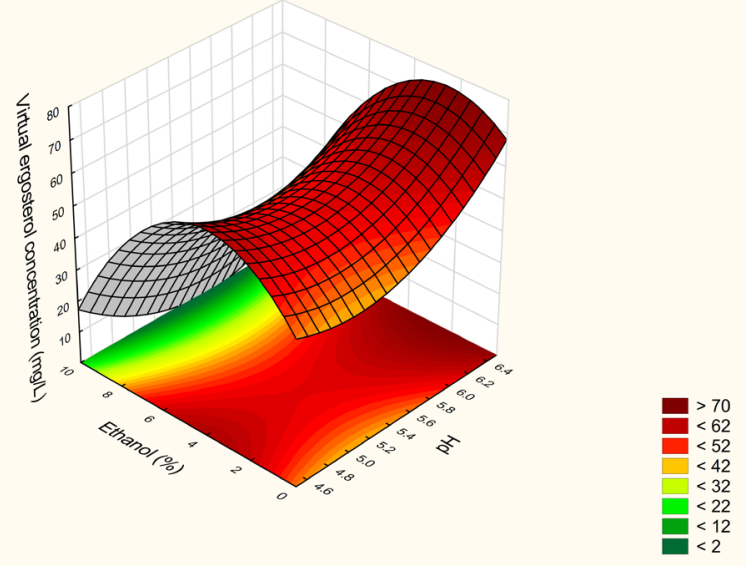

Fig. 6 Virtual ergosterol concentration as a function of ethanol and $\mathrm{pH}$

which our results in Fig. 2 also confirmed: above an initial alcohol content of $8 \%$, the virtual ergosterol concentration results were significantly lower.

The temperature was significant in terms of the virtual ergosterol concentration which is mainly dependent on biomass growth. Here also it can be seen that the highest value, $55 \mathrm{mg} / \mathrm{L}$ was obtained by initially adding $3 \%$ alcohol. This could affirm that it was worthwhile examining reproductive and productive conditions together. It can be seen in Fig. 7 that lower temperatures within the studied temperature range favour higher virtual ergosterol concentrations.

Since Figs. 1, 3 and 5 indicated no significant effect of $\mathrm{pH}$ we decided to investigate it again with wider range. Therefore, $\mathrm{pH}$ was tested in the next experiment along with the effect of the $\mathrm{NaCl}$ concentration as an additional factor.

Interestingly, neither the $\mathrm{pH}$ nor salt concentration had a significant effect on yeast growth within the studied range. Therefore, it is possible to adjust the $\mathrm{pH}$ to a value that is beneficial with regard to the production of ergosterol.

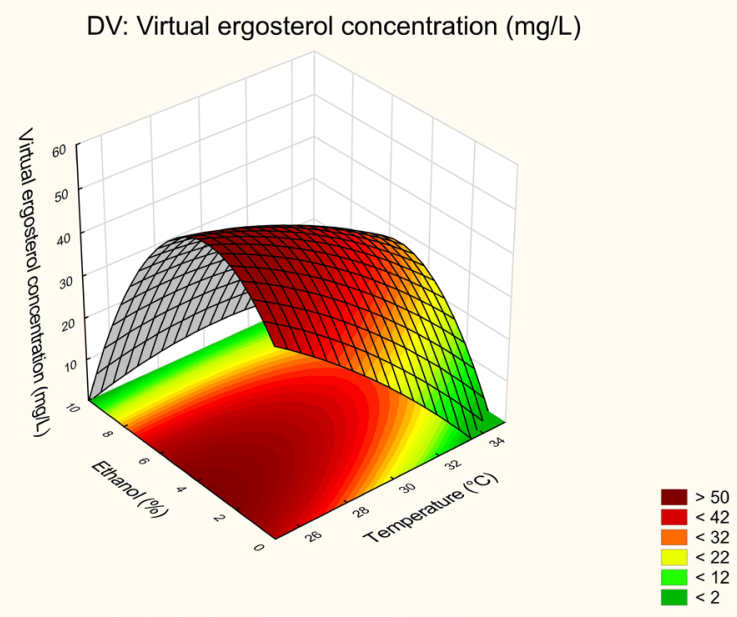

Fig. 7 Virtual ergosterol concentration as a function of ethanol and temperature

On the other hand, in terms of the ergosterol content of the cells, the effect of the $\mathrm{pH}$ proved to be significant quadratically as can be seen in Fig. 8.

By depicting how the specific ergosterol content of the cells changed at different $\mathrm{pH}$ values, a response surface was drawn and presented in Fig. 9. At the extreme values within the studied range, the minimum specific ergosterol contents were observed, while within the middle $\mathrm{pH}$ range, the maximum specific ergosterol contents were recorded at almost every salt concentration. The highest value was obtained at pH 5.3, which was $8.05 \mathrm{mg} / \mathrm{g}$. Specific ergosterol content is rarely published (mostly ergosterol yield i.e. virtual concentration is given) for $K$. marxianus. The only available result was found as $0.7 \mathrm{mg} / \mathrm{g}$ [1], which is significant lower value then our result. However, industrial ergosterol fermentations generally use $S$. cerevisiae, of which reported specific ergosterol content is around

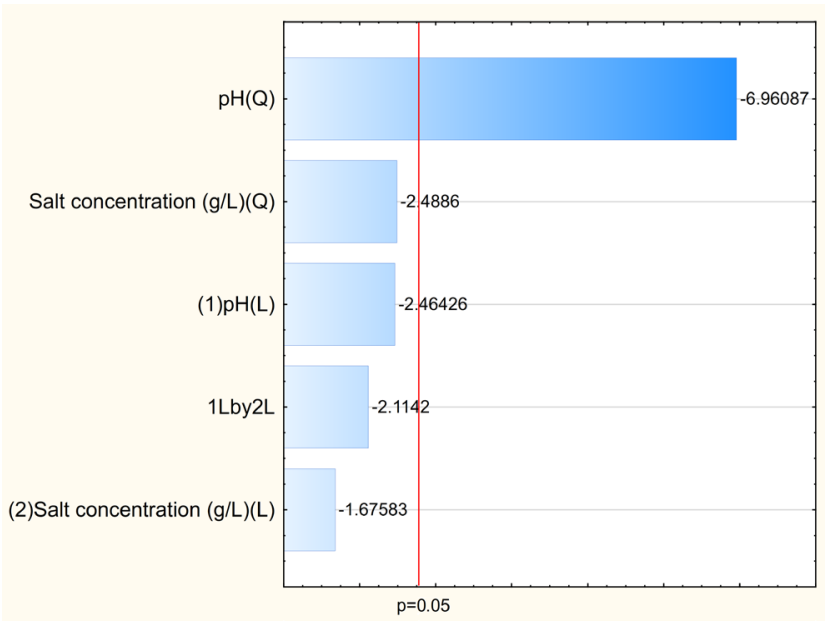

Fig. 8 Pareto chart of the ergosterol content of cells in the second experimental design (L: Linear, Q: Quadratic) 
DV: Specific ergosterol content $(\mathrm{mg} / \mathrm{g})$

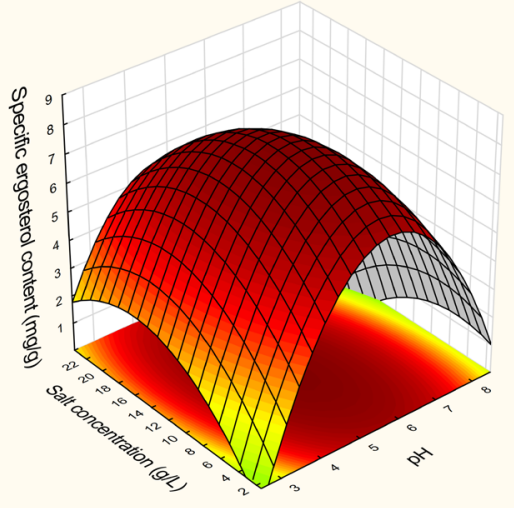

DV: Ergosterol concentration (mg/L)

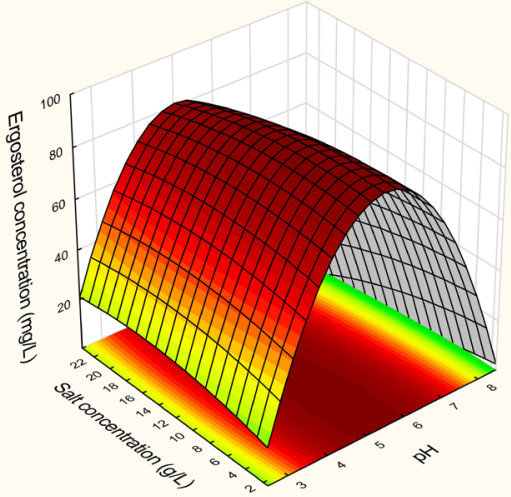

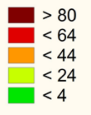

Fig. 11 Virtual ergosterol concentration as a function of salt concentration and $\mathrm{pH}$
$25 \mathrm{mg} / \mathrm{g}$ [30]. The fact that the salt concentration had no significant effect on the ergosterol content was confirmed since it hardly changed at different salt concentrations.

Since neither of the two factors had any significant effect on yeast growth, a similar result was expected in terms of the virtual ergosterol concentration as was observed with regard to the specific ergosterol content. Only the quadratic function of $\mathrm{pH}$ was found to be a significant factor in the absence of its former linear part as can be seen in Fig. 10.

The response surface was similar to the previous case (i.e. specific ergosterol content): the salt concentration did not significantly affect the virtual ergosterol concentration as is shown in Fig. 11. Our hypothesis was that cells respond to osmotic stress by increasing the ergosterol content of the cell membrane. No such research could be found in the literature. The effect of osmotic stress caused by glucose,

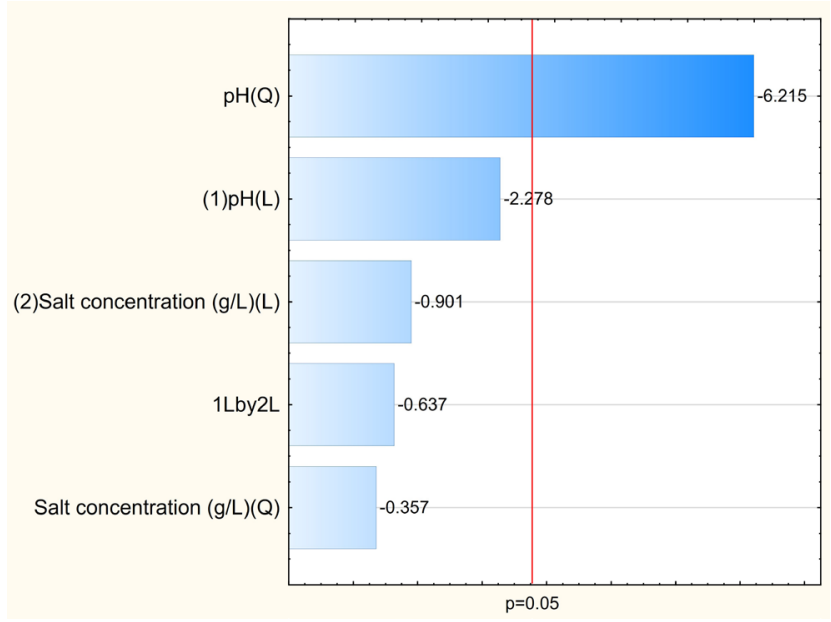

Fig. 10 Pareto chart of the virtual ergosterol concentration in the second experimental design (L: Linear, Q: Quadratic) lactose [35, 36], and $\mathrm{NaCl}[37]$ on cells has been studied, however, in neither case was the amount of ergosterol or related gene regulation investigated. Lane et al. [38] showed that certain strains of $K$. marxianus were tolerant against different $\mathrm{NaCl}$ concentrations, however, no growth was observed in either case with $1 \mathrm{M} \mathrm{NaCl}$ solution.

In our results, the effect of $\mathrm{NaCl}$ concentration did not prove to be significant in the studied range, therefore, it can be concluded that this strain belongs to the group that are tolerant up to $0.5 \mathrm{M} \mathrm{NaCl}$ concentration. It may be worthwhile to investigate the effect of osmotic stress caused by different carbon sources and salts on the regulation of ergosterol content. The highest values, around $85 \mathrm{mg} / \mathrm{L}$ were reached around $\mathrm{pH} 5.3$, which was the same as the $\mathrm{pH}$ optimum of the specific ergosterol content.

The interaction between the two factors and the effect of the salt concentration were insignificant in both cases in the second experimental design.

Verification experiments resulted in $82.3 \pm 3.6 \mathrm{mg} / \mathrm{L}$ ergosterol content in three parallel runs at $25^{\circ} \mathrm{C}$ and pH 5.5.

\section{Conclusion}

In summary, four factors were examined by two statistical experimental designs with regard to yeast growth and the ergosterol content of K. marxianus Y00243. Only temperature proved to be significant for yeast growth and had a negative effect on it. In terms of the specific ergosterol content of yeast, quadratic function of the added alcohol and the quadratic function of the $\mathrm{pH}$ (over a wide $\mathrm{pH}$ range) as well as the interaction between the alcohol and temperature proved to be significant. All these factors had a positive effect on the specific ergosterol content. Since the factors acted 
differently on biomass concentration and specific ergosterol content, therefore a combined effect was evaluated through virtual ergosterol concentration (ergosterol content extracted in $\mathrm{mg} /$ volume of fermentation broth used in L). This evaluation proved the significance of the alcohol, temperature and $\mathrm{pH}$ (when a wider $\mathrm{pH}$ range was considered) as well as interactions between the temperature and alcohol in addition to between the $\mathrm{pH}$ and alcohol. The tested salt concentrations were not found to be significant in any of the tested setups.

\section{References}

[1] Diniz, R. H. S., Villada, J. C., Alvim, M. C. T., Vidigal, P. M. P., Vieira, N. M., Lamas-Maceiras, M., Cerdán, M. E., GonzálezSiso, M.-I., Lahtbee, P.-J., da Silveira, W. B. "Transcriptome analysis of the thermotolerant yeast Kluyveromyces marxianus CCT 7735 under ethanol stress", Applied Microbiology and Biotechnology, 101(18), pp. 6969-6980, 2017.

https://doi.org/10.1007/s00253-017-8432-0

[2] Mareczky, Z., Fehér, A., Fehér, C., Barta, Z., Réczey, K. "Effects of $\mathrm{pH}$ and Aeration Conditions on Xylitol Production by Candida and Hansenula Yeasts", Periodica Polytechnica Chemical Engineering, 60(1), pp. 54-59, 2016.

https://doi.org/10.3311/PPch.8116

[3] Colombo, L. T., Rosa, J. C. C., Bragança, C. R. S., Ignacchiti, R. P., Alvim, M. C. T., Silveira, W. B., de Queiroz, M. V., Bazzolli, D. M. S., Passos, F. M. L. "Construction of a Kluyveromyces lactis ku $80^{-}$Host Strain for Recombinant Protein Production: Extracellular Secretion of Pectin Lyase and a Streptavidin-Pectin Lyase Chimera", Molecular Biotechnology, 56(4), pp. 319-328, 2014.

https://doi.org/10.1007/s12033-013-9711-3

[4] Diniz, R. H. S., Rodrigues, M. Q. R. B., Fietto, L. G., Passos, F. M. L., Silveira, W. B. "Optimizing and validating the production of ethanol from cheese whey permeate by Kluyveromyces marxianus UFV-3", Biocatalysis and Agricultural Biotechnology, 3(2), pp. 111-117, 2014. https://doi.org/10.1016/j.bcab.2013.09.002

[5] Rocha, S. N., Abrahão-Neto, J., Cerdán, M. E., GonzálezSiso, M. I., Gombert, A. K. "Heterologous expression of glucose oxidase in the yeast Kluyveromyces marxianus", Microbial Cell Factories, 9(1), Article number: 4, 2010.

https://doi.org/10.1186/1475-2859-9-4

[6] Rocha, S. N., Abrahão-Neto, J., Cerdán, M. E., Gombert, A. K., González-Siso, M. I. "Heterologous expression of a thermophilic esterase in Kluyveromyces yeasts", Applied Microbiology and Biotechnology, 89(2), pp. 375-385, 2011.

https://doi.org/10.1007/s00253-010-2869-8

[7] Silveira, W. B., Passos, F. J. V., Mantovani, H. C., Passos, F. M. L. "Ethanol production from cheese whey permeate by Kluyveromyces marxianus UFV-3: A flux analysis of oxido-reductive metabolism as a function of lactose concentration and oxygen levels", Enzyme and Microbial Technology, 36(7), pp. 930-936, 2005.

https://doi.org/10.1016/j.enzmictec.2005.01.018

[8] Zafar, S., Owais, M. "Ethanol production from crude whey by Kluyveromyces marxianus", Biochemical Engineering Journal, 27(3), pp. 295-298, 2006.

https://doi.org/10.1016/j.bej.2005.05.009
The best value of virtual ergosterol concentration was observed at $25{ }^{\circ} \mathrm{C}, \mathrm{pH} 4.5$ and $3 \%$ initially added ethanol, resulting in $80.8 \mathrm{mg} / \mathrm{L}$ ergosterol. This value is significantly lower than corresponding reported ergosterol yield (500$1700 \mathrm{mg} / \mathrm{L}$ ) [39], but the reached biomass amount was also much higher or genetically modified in that papers. Therefore, we have to increase the use carbon source amount to reach higher cell concentration which can enhance the extractable amount of ergosterol per $\mathrm{L}$ fermentation broth as well.

[9] Tofalo, R., Fasoli, G., Schirone, M., Perpetuini, G., Pepe, A., Corsetti, A., Suzzi, G. "The predominance, biodiversity and biotechnological properties of Kluyveromyces marxianus in the production of Pecorino di Farindola cheese", International Journal of Food Microbiology, 187, pp. 41-49, 2014. https://doi.org/10.1016/j.ijfoodmicro.2014.06.029

[10] Goshima, T., Negi, K., Tsuji, M., Inoue, H., Yano, S., Hoshino, T., Matsushika, A. "Ethanol fermentation from xylose by metabolically engineered strains of Kluyveromyces marxianus", Journal of Bioscience and Bioengineering, 116(5), pp. 551-554, 2013. https://doi.org/10.1016/j.jbiosc.2013.05.010

[11] Fonseca, G. G., Heinzle, E., Wittmann, C., Gombert, A. K. "The yeast Kluyveromyces marxianus and its biotechnological potential", Applied Microbiology and Biotechnology, 79(3), pp. 339-354, 2008.

https://doi.org/10.1007/s00253-008-1458-6

[12] Marcišauskas, S., Ji, B., Nielsen, J. "Reconstruction and analysis of a Kluyveromyces marxianus genome-scale metabolic model", BMC Bioinformatics, 20(1), Article number: 551, 2019. https://doi.org/10.1186/s12859-019-3134-5

[13] Lane, M. M., Morrissey, J. P. "Kluyveromyces marxianus: A yeast emerging from its sister's shadow", Fungal Biology Reviews, 24(1-2), pp. 17-26, 2010. https://doi.org/10.1016/j.fbr.2010.01.001

[14] Zhang, K., Tong, M., Gao, K., Di, Y., Wang, P., Zhang, C., Wu, X., Zheng, D. "Genomic reconstruction to improve bioethanol and ergosterol production of industrial yeast Saccharomyces cerevisiae", Journal of Industrial Microbiology and Biotechnology, 42(2), pp. 207-218, 2015. https://doi.org/10.1007/s10295-014-1556-7

[15] Papoutsis, K., Grasso, S., Menon, A., Brunton, N. P., Lyng, J. G., Jacquier, J.-C., Bhuyan, D. J. "Recovery of ergosterol and vitamin $\mathrm{D}_{2}$ from mushroom waste - Potential valorization by food and pharmaceutical industries", Trends in Food Science and Technology, 99, pp. 351-366, 2020. https://doi.org/10.1016/j.tifs.2020.03.005

[16] Blaga, A. C., Ciobanu, C., Caşcaval, D., Galaction, A.-I. "Enhancement of ergosterol production by Saccharomyces cerevisiae in batch and fed-batch fermentation processes using $n$-dodecane as oxygen-vector", Biochemical Engineering Journal, 131, pp. 70-76, 2018. https://doi.org/10.1016/j.bej.2017.12.010 
[17] Johnston, E. J., Moses, T., Rosser, S. J. "The wide-ranging phenotypes of ergosterol biosynthesis mutants, and implications for microbial cell factories", Yeast, 37(1), pp. 27-44, 2020. https://doi.org/10.1002/yea.3452

[18] Bhattacharya, S., Esquivel, B. D., White, T. C. "Overexpression or Deletion of Ergosterol Biosynthesis Genes Alters Doubling Time, Response to Stress Agents, and Drug Susceptibility in Saccharomyces cerevisiae", mBio, 9(4), Article number: e01291-18, 2018. https://doi.org/10.1128/mBio.01291-18

[19] Jordá, T., Puig, S. "Regulation of Ergosterol Biosynthesis in Saccharomyces cerevisiae", Genes, 11(7), Article number: 795, 2020. https://doi.org/10.3390/genes11070795

[20] Rodrigues, M. L. "The Multifunctional Fungal Ergosterol", mBio, 9(5), Article number: e01755-18, 2018. https://doi.org/10.1128/mBio.01755-18

[21] Liu, J.-F., Xia, J.-J., Nie, K.-L., Wang, F., Deng, L. "Outline of the biosynthesis and regulation of ergosterol in yeast", World Journal of Microbiology and Biotechnology, 35(7), Article number: 98, 2019. https://doi.org/10.1007/s11274-019-2673-2

[22] Prasad, R., Shah, A. H., Rawal, M. K. "Antifungals: Mechanism of Action and Drug Resistance", In: Ramos, J., Sychrová, H., Kschischo, M. (eds.) Yeast Membrane Transport, Springer, Cham, Switzerland, 2016, pp. 327-349. https://doi.org/10.1007/978-3-319-25304-6 14

[23] Kitchawalit, S., Kanokmedhakul, K., Kanokmedhakul, S., Soytong, K. "A new benzyl ester and ergosterol derivatives from the fungus Gymnoascus reessii", Natural Product Research, 28(14), pp. 1045-1051, 2014. https://doi.org/10.1080/14786419.2014.903478

[24] Vil, V. A., Gloriozova, T. A., Poroikov, V. V., Terent'ev, A. O., Savidov, N., Dembitsky, V. M. "Peroxy steroids derived from plant and fungi and their biological activities", Applied Microbiology and Biotechnology, 102(18), pp. 7657-7667, 2018. https://doi.org/10.1007/s00253-018-9211-2

[25] Liu, G., Chen, Y., Færgeman, N. J., Nielsen, J. "Elimination of the last reactions in ergosterol biosynthesis alters the resistance of Saccharomyces cerevisiae to multiple stresses", FEMS Yeast Research, 17(6), Article number: fox063, 2017. https://doi.org/10.1093/femsyr/fox063

[26] Hu, Z., He, B., Ma, L., Sun, Y., Niu, Y., Zeng, B. "Recent Advances in Ergosterol Biosynthesis and Regulation Mechanisms in Saccharomyces cerevisiae", Indian Journal of Microbiology, 57(3), pp. 270-277, 2017. https://doi.org/10.1007/s12088-017-0657-1

[27] Thakur, A., Panesar, P. S., Saini, M. S. "Parametric Optimization of Lactic Acid Production by Immobilized Lactobacillus casei Using Box-Behnken Design", Periodica Polytechnica Chemical Engineering, 62(3), pp. 274-285, 2018. https://doi.org/10.3311/PPch.11403

[28] Shang, F., Wen, S., Wang, X., Tan, T. "High-cell-density fermentation for ergosterol production by Saccharomyces cerevisiae", Journal of Bioscience and Bioengineering, 101(1), pp. 38-41, 2006. https://doi.org/10.1263/jbb.101.38

[29] Náhlík, J., Hrnčiřík, P., Mareš, J., Rychtera, M., Kent, C. A. "Towards the design of an optimal strategy for the production of ergosterol from Saccharomyces cerevisiae yeasts", Biotechnology Progress, 33(3), pp. 838-848, 2017. https://doi.org/10.1002/btpr.2436
[30] Shang, F., Wen, S., Wang, X., Tan, T. "Effect of nitrogen limitation on the ergosterol production by fed-batch culture of Saccharomyces cerevisiae", Journal of Biotechnology, 122(3), pp. 285-292, 2006. https://doi.org/10.1016/j.jbiotec.2005.11.020

[31] Fisher, R. A., Bioferm Corp. "Extraction of Ergosterol and Ergosterol-like Sterols from Yeast and Analogous Products", United States, US2865934A, 1958. [online] Available at: https:// patentimages.storage.googleapis.com/9f/a4/34/691d1e2078bc38/ US2865934.pdf [Accessed: 05 May 2021]

[32] Aktaş, N., Boyaci, I. H., Mutlu, M., Tanyolaç, A. "Optimization of lactose utilization in deproteinated whey by Kluyveromyces marxianus using response surface methodology (RSM)", Bioresource Technology, 97(18), pp. 2252-2259, 2006. https://doi.org/10.1016/j.biortech.2005.10.039

[33] Costa, D. A., de Souza, C. J. A., Costa, P. S., Rodrigues, M. Q. R. B., dos Santos, A. F., Lopes, M. R., Genier, H. L. A., Silveira, W. B., Fietto, L. G. "Physiological characterization of thermotolerant yeast for cellulosic ethanol production", Applied Microbiology and Biotechnology, 98(8), pp. 3829-3840, 2014. https://doi.org/10.1007/s00253-014-5580-3

[34] Fu, X., Li, P., Zhang, L., Li, S. "Understanding the stress responses of Kluyveromyces marxianus after an arrest during high-temperature ethanol fermentation based on integration of RNA-Seq and metabolite data", Applied Microbiology and Biotechnology, 103(6), pp. 2715-2729, 2019. https://doi.org/10.1007/s00253-019-09637-X

[35] Saini, P., Beniwal, A., Vij, S. "Physiological response of Kluyveromyces marxianus during oxidative and osmotic stress", Process Biochemistry, 56, pp. 21-29, 2017. https://doi.org/10.1016/j.procbio.2017.03.001

[36] Saini, P., Beniwal, A., Kokkiligadda, A., Vij, S. "Evolutionary adaptation of Kluyveromyces marxianus strain for efficient conversion of whey lactose to bioethanol", Process Biochemistry, 62, pp. 69-79, 2017. https://doi.org/10.1016/j.procbio.2017.07.013

[37] Zhang, B., Ren, L., Wang, H., Xu, D., Zeng, X., Li, F. "Glycerol uptake and synthesis systems contribute to the osmotic tolerance of Kluyveromyces marxianus", Enzyme and Microbial Technology, 140, Article number: 109641, 2020. https://doi.org/10.1016/j.enzmictec.2020.109641

[38] Lane, M. M., Burke, N., Karreman, R., Wolfe, K. H., O'Byrne, C. P., Morrissey, J. P. "Physiological and metabolic diversity in the yeast Kluyveromyces marxianus", Antonie van Leeuwenhoek, International Journal of General and Molecular Microbiology, 100(4), pp. 507-519, 2011. https://doi.org/10.1007/s10482-011-9606-x

[39] da Silveira, F. A., de Oliveira Soares, D. L., Bang, K. W., Balbino, T. R., de Moura Ferreira, M. A., Diniz, R. H. S., de Lima, L. A., Brandão, M. M., Villas-Bôas, S. G., da Silveira, W. B. "Assessment of ethanol tolerance of Kluyveromyces marxianus CCT 7735 selected by adaptive laboratory evolution", Applied Microbiology and Biotechnology, 104(17), pp. 7483-7494, 2020. https://doi.org/10.1007/s00253-020-10768-9 